\title{
AS NUANCES DA RESPONSABILIDADE CIVIL DO ESTADO EM MATÉRIA AMBIENTAL FRENTE AOS DANOS DECORRENTES DE IMPACTOS PROVOCADOS POR FENÔMENOS NATURAIS
}

\author{
NUANCES OF THE STATE'S LIABILITY IN ENVIRONMENTAL MATTER \\ FRONT THE NATURAL PHENOMENA'S DAMAGE \\ Elcio Nacur Rezende \\ Escola Superior Dom Helder Câmara - Belo Horizonte - Minas Gerais - Brasil \\ Henrique Rosmaninho Alves \\ Escola Superior Dom Helder Câmara - Belo Horizonte - Minas Gerais - Brasil
}

\begin{abstract}
Resumo: Apresenta-se como problema a ser resolvido pelo presente estudo a (im)possibilidade de responsabilização do Estado pelos danos sofridos pelos administrados provocados por fenômenos naturais. Em decorrência da responsabilidade civil objetiva adotada pela Constituição da República no que tange à atuação estatal e ao meio ambiente, adotou-se como hipótese a possibilidade do Estado ser responsável civilmente pelos danos provocados por eventos naturais independentemente de culpa. Trata-se de um estudo jurídico-teórico no qual predominaram pesquisas bibliográficas, relativas à doutrina de Direito Ambiental e Responsabilidade Civil, de dados dos órgãos oficiais de defesa civil, e a análise das normas positivadas de proteção ambiental, gestão de riscos de desastres e ordenação urbanística. Adota-se como marco teórico as Leis 10.257/2001 e 12.608/2012, a concepção de gestão de riscos de desastres de Delton Winter de Carvalho e Fernanda Dalla Libera Damacena, e a noção de responsabilidade civil de Clarisse Ferreira Jardim, Sergio Cavalieri Filho, José Rubens Morato Leite, Patryck Ayala e Delton Winter de Carvalho. Acredita-se que o presente estudo pode contribuir efetivamente para a comunidade acadêmica, por versar sobre tema pouco estudado e para a sociedade em geral, por buscar a resolução de um problema que afeta grande parcela da população nos seus direitos mais essenciais.
\end{abstract}

Palavras-chave: Desastres Naturais; Responsabilidade Civil; Dano Ambiental.

Abstract: The present study aim to discuss the (im)possibility of the accountability of the State by the damages caused by natural phenomena to the civil user. Due to the liability adopted by the Brazilian Constitution, which regards to State's action and the environment, it is adopted as a hypothesis the possibility of the State being civilly charged by the damage of natural disasters regardless of fault. This study adopts a legal-theoretical approach in which were done the revision of the literature that concerns to the Environmental Law and Liability, the analysis of the official data from the Civil Defense department, the standards about environmental protection, risk and disaster management, and urban planning. Is adopted as a theoretical framework the national Law № 
$10.257 / 2001$ and Law № $12.608 / 2012$, the approach of management of the risk and disaster by Delton Winter de Carvalho and Fernanda Dalla Libera Damacena, and the idea of liability proposed by Clarisse Ferreira Jardim, Sergio Cavalieri Filho, José Rubens Morato Leite, Patryck Ayala, and Delton Winter de Carvalho. Is considered that the present study can effectively contribute to the academic community since it discuss a non-widely study topic and aim to find resolution to problem that affects part of the society's basic rights.

Keywords: Natural Disasters; Liability; Environmental Damage.

\section{Introdução}

Os danos ambientais resultantes de fenômenos naturais vêm crescendo paulatinamente nos últimos anos no Brasil conforme se verifica da análise do Atlas Brasileiro de Desastres Naturais 1991-2010 e dos Anuários Brasileiros de Desastres Naturais de 2011 e 2012 . Diante desse cenário de degradação é imprescindível verificar a responsabilidade estatal, visto que o Estado tem por dever a proteção e preservação do meio ambiente e a garantia de uma vida digna aos seus administrados, nos termos do artigo 225 da Constituição, ao passo que também é portador de maiores recursos que se aplicados podem diminuir os encargos dos atingidos.

Busca-se ao longo do texto identificar se em casos de danos ambientais (patrimoniais e extrapatrimoniais) provocados pelos impactos de fenômenos naturais, configurar-se-á a responsabilidade civil do Estado e de que modo essa responsabilidade se dará.

Trata-se de um estudo jurídico-teórico no qual foram investigados os aspectos da responsabilidade civil do Estado em casos de danos provocados por desastres naturais. Investigou-se quais são os deveres legais de atuação do Estado no intuito de minimizar a vulnerabilidade a eventos naturais e qual a relação entre a omissão estatal e a concretização do dano, para então adentrar nos aspectos jurídicos e práticos da responsabilidade civil do Estado em matéria ambiental. Predominaram os estudos bibliográficos, relativos à doutrina de Direito Ambiental e Responsabilidade Civil e a análise de dados dos órgãos oficiais de defesa civil. 
Adota-se como marco teórico as Leis 10.257/2001 e 12.608/2012, a concepção de gestão de riscos de Delton Winter de Carvalho e Fernanda Dalla Libera Damacena, e a noção de responsabilidade civil dos autores Clarisse Ferreira Jardim, Sergio Cavalieri Filho, José Rubens Morato Leite, Patryck Ayala e Delton Winter de Carvalho.

A fim de proporcionar maior clareza de raciocínio dividiu-se o presente estudo em 5 capítulos.

O primeiro capítulo destina-se a demonstrar como os desastres naturais podem ser causas de danos socioambientais. Nesse momento apresentam-se os tipos de fenômenos naturais ensejadores de danos mais frequentes no Brasil e no mundo e quais são as espécies de danos mais comuns no país.

No segundo momento busca-se expor quais são os deveres estatais relativos à prevenção de desastres. Para tanto, aborda-se no segundo capítulo as competências constitucionais dos entes federados em matéria ambiental e urbanística, para posteriormente, no terceiro capítulo identificar quais são os deveres específicos (presentes nas leis no 10257/2001 e 12.608/2012) de atuação do Estado na gestão de riscos de desastres naturais.

O quarto capítulo versa sobre responsabilidade civil, iniciando com uma introdução aos aspectos gerais do tema, para posteriormente discutir-se os pontos mais polêmicos do instituto.

No derradeiro capítulo menciona-se as interferências dos princípios da precaução e da prevenção em matéria de responsabilidade civil do Estado em casos de desastres naturais.

Acredita-se que o presente estudo possa trazer importantes contribuições para a comunidade acadêmica, tanto por versar sobre assunto ainda pouco debatido como por não conseguir embora não esgotar o tema, o que deixa espaço para futuras observações acerca de pontos cruciais da responsabilização do Estado por danos oriundos dos impactos de fenômenos naturais.

\section{Os desastres naturais como a causa de danos socioambientais}


Os desastres naturais são responsáveis anualmente por consideráveis prejuízos para a humanidade, que subdividem-se em danos patrimoniais (destruição de residências por deslizamentos, por ex.) e extrapatrimoniais (óbitos, enfermidades, ferimentos leves e graves, por ex.).

A elevação da incidência de desastre naturais em todo o planeta fez com que o Programa das Nações Unidas para o Desenvolvimento - PNUD os elencasse no Relatório de Desenvolvimento Humano 2014 como uma das seis principais ameaças ao desenvolvimento.

No Brasil o Decreto 7.257/2010 definiu desastres em seu artigo 2을, inciso II, como "resultado de eventos adversos, naturais ou provocados pelo homem sobre um ecossistema vulnerável, causando danos humanos, materiais ou ambientais e consequentes prejuízos econômicos e sociais". (BRASIL, 2010)

O Instituto de Pesquisas Espaciais conceituou desastres naturais como "o resultado de eventos adversos que causam grandes impactos na sociedade [...] são causados pelo impacto de um fenômeno natural de grande intensidade sobre uma área ou região povoada, podendo ou não ser agravado pelas atividades antrópicas". (BRASIL, 2007, p.5)

O Ministério da Integração, na Política Nacional de Defesa Civil de 2007 determinou que os desastres naturais "são aqueles provocados por fenômenos e desequilíbrios da natureza. São produzidos por fatores de origem externa que atuam independentemente da ação humana." (BRASÍLIA, 2007)

Diversos fenômenos naturais podem ser responsáveis por impactos que resultem em danos materiais, humanos e ambientais, como as enchentes, terremotos, avalanches, seca, deslizamentos de terra, tsunamis, furacões, erupções vulcânicas, vendavais, entre outros.

O Instituto Nacional de Pesquisas Espaciais catalogou os tipos de fenômenos naturais mais recorrentes em todos os continentes e no Brasil: 


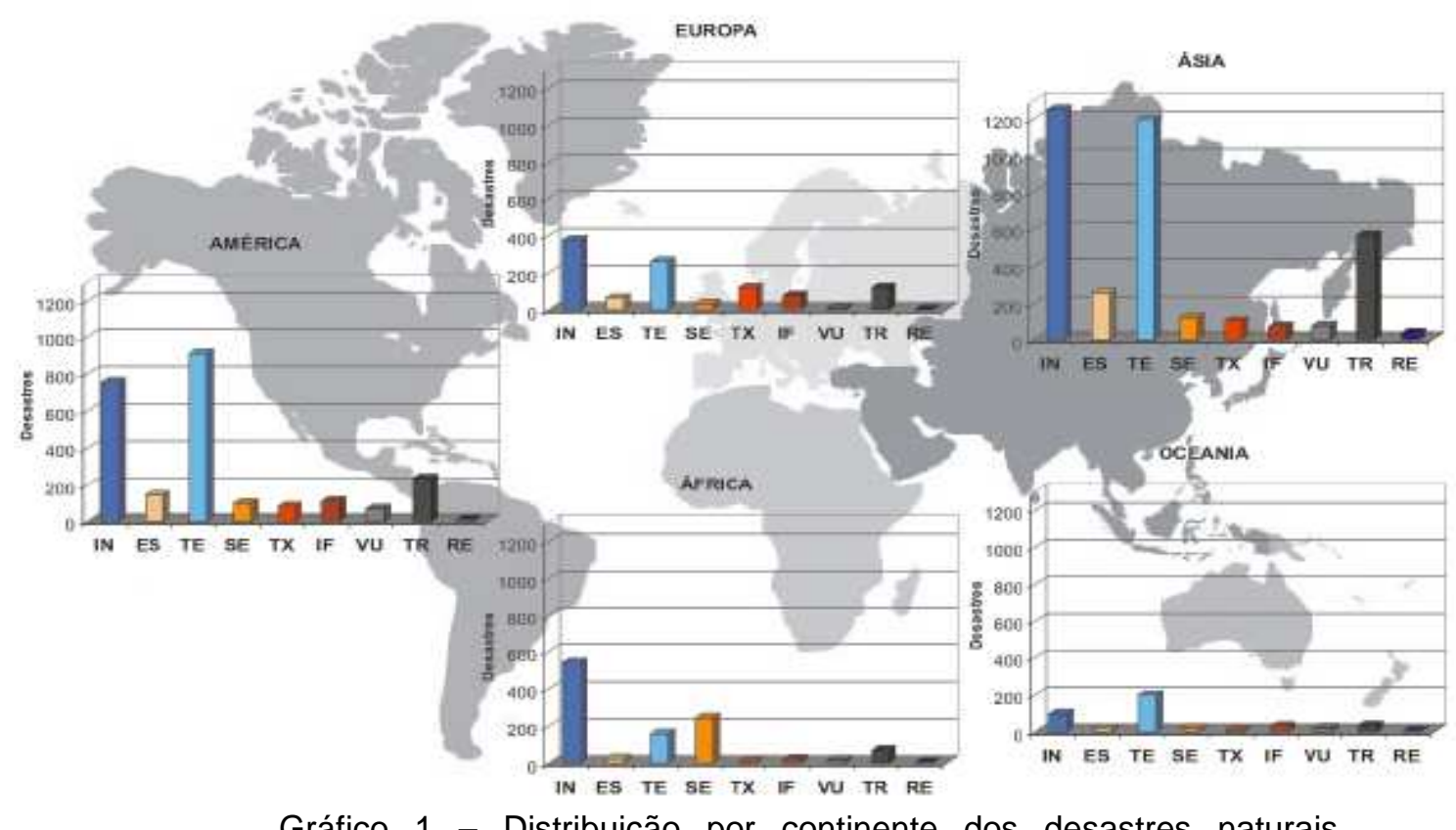

Gráfico 1 - Distribuição por continente dos desastres naturais ocorridos no globo (1900-2006)

Legenda: IN - inundação, ES - escorregamento, TE - tempestade, SE - seca, TX - temperatura extrema, IF - incêndio florestal, VU vulcanismo, TR - terremoto e RE - ressaca.

Fonte: (BRASIL, 2007, p.7)

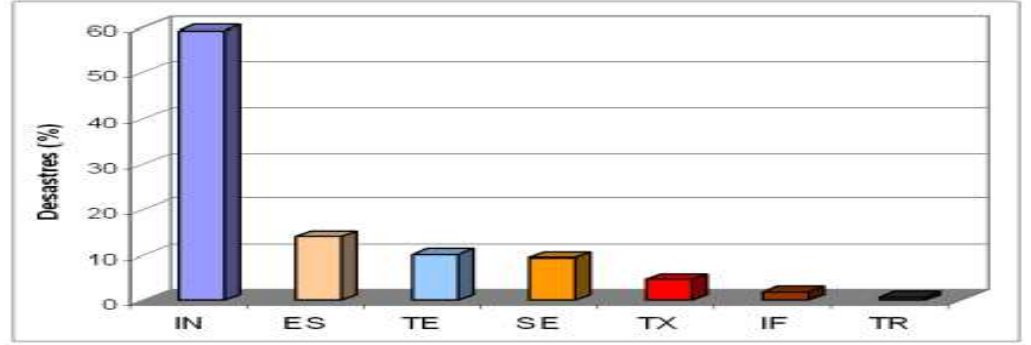

Gráfico 2 - Tipos de Desastres Naturais ocorridos no Brasil (19002006)

Legenda: IN - inundação, ES - escorregamento, TE - tempestade, $\mathrm{SE}-\mathrm{seca}$,

TX - temperatura extrema, IF - incêndio florestal, TR - terremoto.

Fonte: (BRASIL, 2007, p.8)

Percebe-se pela leitura do gráfico 2 que as inundações, escorregamentos de terra e tempestades são os eventos naturais responsáveis por desastres mais recorrentes no Brasil.

Os fenômenos naturais devido à sua força e imprevisibilidade (muito mitigada pelo avanço tecnológico) possuem grande poder de destruição, ocasionando os mais variados danos à população.

O Ministério da Integração, por intermédio do Centro Nacional de Gerenciamento de Riscos e Desastres elaborou o Anuário Brasileiro de 
Desastres Naturais relativos aos anos de 2011 e 2012, em que se verificaram quais são os fenômenos naturais responsáveis pelos maiores danos à população brasileira.

\begin{tabular}{|c|c|c|c|c|c|c|c|c|}
\hline Eventos & Óbitos & Feridos & Enfermos & Desabrigados & Desalojados & Desaparecidos & Afetados & $\begin{array}{c}\text { Quantidade } \\
\text { de Muricipios } \\
\text { Afetados }\end{array}$ \\
\hline Enxurradas & 518 & 304 & 306 & 52.832 & 247.726 & 2 & 7.043 .989 & 944 \\
\hline Inundação & 79 & 195 & 104 & 49.644 & 315.885 & 0 & 2.050 .431 & 515 \\
\hline Seca & 3 & 10 & 9.553 & 10 & 76 & 0 & 1.308 .873 & 234 \\
\hline Vendaval & 16 & 108 & 30 & 1.742 & 12.812 & 0 & 900.309 & 236 \\
\hline Deslizamentos & 472 & 11 & 0 & 7.228 & 44.519 & 0 & 676.388 & 161 \\
\hline Granizo & 0 & 33 & 2 & 938 & 20.632 & 0 & 214.461 & 130 \\
\hline Alagamentos & 1 & 11 & 0 & 2.874 & 13.287 & 3 & 179.133 & 92 \\
\hline Erosăo & 0 & 0 & 0 & 0 & 190 & 0 & 92.508 & 25 \\
\hline Chuvas Intensas & 2 & 0 & 0 & 271 & 649 & 0 & 27.036 & 21 \\
\hline Ressaca & 0 & 0 & 2 & 0 & 176 & 0 & 21.268 & 5 \\
\hline Friagem & 2 & 0 & 564 & 0 & 0 & 0 & 20.004 & 4 \\
\hline Geada & 0 & 0 & 0 & 0 & 0 & 0 & 1.000 & 2 \\
\hline $\begin{array}{c}\text { Tempestades } \\
\text { de Raios }\end{array}$ & 1 & 0 & 0 & 0 & 0 & 0 & 1 & 1 \\
\hline Total & 1.094 & 672 & 10.561 & 115.539 & 655.952 & 5 & 12.535 .401 & 2.370 \\
\hline
\end{tabular}

Tabela 1: Danos Humanos por Tipo de Evento de Desastre - 2011 Fonte: (BRASIL, 2012, p.33)

\begin{tabular}{|c|c|c|c|c|c|c|c|}
\hline EVENTOS & Óbitos & Feridos & Enfermos & Desabrigados & Desalojados & Desaparecidos & Afetados \\
\hline Seca/Estiagem & 6 & 0 & 14.214 & 30 & 750 & 0 & 8.956 .853 \\
\hline $\begin{array}{c}\text { Incêndio } \\
\text { Florestal }\end{array}$ & 0 & 0 & 0 & 0 & 0 & 0 & 37.338 \\
\hline $\begin{array}{c}\text { Movimentos } \\
\text { de massa }\end{array}$ & 26 & 10 & 2 & 1.129 & 2.801 & 0 & 123.555 \\
\hline Erosão & 0 & 0 & 5 & 81 & 2.105 & 0 & 55.653 \\
\hline Alagamentos & 5 & 6 & 6 & 1.048 & 954 & 0 & 24.581 \\
\hline Enxurradas & 26 & 6.580 & 14.318 & 49.769 & 262.851 & 2 & 1.856 .359 \\
\hline Inundações & 14 & 2.409 & 10.665 & 52.041 & 216.349 & 2 & 5.185 .018 \\
\hline Geadas & 0 & 0 & 0 & 0 & 0 & 0 & 30.777 \\
\hline Granizo & 0 & 11 & 4 & 418 & 7.971 & 1.040 & 103.265 \\
\hline Tornados & 0 & 2 & 0 & 1 & 20 & 0 & 4.310 \\
\hline Vendaval & 16 & 150 & 13 & 5.769 & 13.220 & 0 & 599.905 \\
\hline TOTAL & 93 & 9.168 & 39.227 & 110.286 & 507.021 & 1.044 & 16.977 .614 \\
\hline
\end{tabular}

Tabela 2: Danos Humanos por tipo de Evento de Desastre - 2012 Fonte: (BRASIL, 2013, p.33)

Nota-se pela análise das tabelas dos Anuários Brasileiros de Desastres Naturais de 2011 e de 2012 que os fenômenos naturais causadores de maiores danos à sociedade são as inundações, enxurradas e deslizamentos de terra/movimentos de massa. Apenas no que tange aos óbitos e aos desabrigados, no biênio 2011/2012 as inundações foram responsáveis por 93 óbitos e 101.685 desabrigados, as enxurradas foram responsáveis por 544 óbitos e 101.601 desabrigados e os deslizamentos de terra/movimentos de massa foram responsáveis por 498 óbitos e 8.357 desabrigados. 
Há que se mencionar que os danos provocados por fenômenos naturais são potencializados por alguns fatores antrópicos, que aumentam a vulnerabilidade de um determinado local ou comunidade aos impactos resultantes dos mesmos.

Delton Winter de Carvalho e Fernanda Dalla Libera Damacena citam 5 fatores de potencialização dos riscos e custos dos desastres na sociedade contemporânea, quais sejam: condições econômicas modernas; mudanças climáticas; destruição de infraestrutura verde e construída; crescimento populacional e tendência demográfica; e decisões acerca da ocupação do solo. (CARVALHO; DAMACENA, 2013) Em estudo denominado "Mapa mental das enchentes urbanas" a Universidade Federal Rural do Rio de Janeiro - UFRRJ identificou como os maiores responsáveis por tais fenômenos a impermeabilização do solo e a disposição inadequada de resíduos sólidos, o que se encaixa na destruição da infraestrutura verde, citada por Carvalho e Damascena. (UFRRJ, 2014)

É notório que a destruição das infraestruturas verdes e construídas, as mudanças climáticas e as decisões acerca da ocupação do solo são matérias de nítido caráter ambiental (destruição das infraestruturas verdes e mudanças climáticas) e urbanístico (destruição das infraestruturas construídas e decisões acerca da ocupação do solo), o que demonstra a necessidade de se conhecer as competências do poder público nessas esferas para a averiguação de eventual responsabilização pelos danos ocorridos em desastres naturais.

\subsection{A relação entre a urbanização brasileira e a vulnerabilidade socioambiental dos centros urbanos}

A urbanização brasileira ocorreu em um curto período de tempo e foi marcada por uma grande explosão demográfica.

Conforme ensinamentos de Milton Santos, em 1920 a população total do Brasil era de 27.500.000 habitantes, sendo que 16,55\% desses residiam em áreas urbanas. Nos cinquenta anos posteriores a população total do país triplicou, enquanto a população urbana aumentou 13 vezes de tamanho. (SANTOS, 2005) 
O grande aumento da população urbana, todavia não foi acompanhado de políticas públicas de habitação e saneamento básico, o que resultou em ocupações irregulares em encostas de morros, beiras de rios e estradas e loteamentos clandestinos, todos desprovidos de serviços básicos como energia elétrica, calçamento, entre outros, que desencadearam no fenômeno conhecido como favelização.

Luiz Paulo Conde afirma que "a ausência do poder público, extremamente burocratizado e elitizado contribuiu para estimular o processo de favelização das cidades". (CONDE, 1992, p.15)

De fato a população de baixa renda, desprovida de recursos para adquirir sua casa própria, na busca desesperada por moradia se instalou em locais vulneráveis às intempéries da natureza, grande parte das vezes distantes dos bairros centrais providos de infraestrutura, mas capazes de possibilitar mão de obra para as cidades, o que atendia o interesse da elite, que possuía oferta de mão de obra barata e não tinha que habitar próxima aos seus empregados.

Nesse sentido Raquel Rolnik defende a existência de um apartheid que dividiu as cidades brasileiras em centro e periferias. Aduz a autora que:

\footnotetext{
O "centro" é o ambiente dotado de infraestrutura completa, onde estão concentrados o comércio, os serviços e os equipamentos culturais; e onde todas as residências de nossa diminuta classe média têm escritura devidamente registrada em cartório. Já a "periferia" é o lugar feito exclusivamente de moradias de pobres, precárias, eternamente inacabadas, e cujos habitantes raramente têm documentos de propriedade. (ROLNIK, 1997, p.200-201)
}

Importa mencionar que embora muitos autores atribuam a desorganização da urbanização brasileira à ausência de planejamento do poder público, Raquel Rolnik e Edésio Fernandes afirmam que foi justamente esse planejamento o grande responsável pelo modo como ela transcorreu:

\footnotetext{
São usuais, nos momentos em que voltam à mídia os dramas da "periferia" e das "favelas", as análises que culpam o Estado por não ter planejado, por não ter políticas habitacionais ou mesmo por ter "se ausentado". Entretanto é flagrante o quanto o planejamento, a política habitacional e de gestão do solo urbano tem contribuído para construir este modelo de exclusão territorial. (ROLNIK, 1997, p.200-201, grifo nosso)
} 
Aqueles municípios que fizeram algum esforço de planejamento urbano fizeram-no de forma a desconsiderar as realidades socioeconômicas das cidades, reservando para os pobres os lugares fora das áreas do mercado, tais como áreas públicas ou ambientalmente inadequadas à presença humana. (FERNANDES, 2006, p.17)

Mariza Rios assevera que em razão de existirem pessoas que moram em locais perigosos, como encostas e beira de rios, "o advento do período pluvial é preocupante em várias regiões. Deixa sem dormir várias famílias e acaba sepultando, em pleno século XXI, inúmeras pessoas." (RIOS, 2012, p.124)

Indubitavelmente o processo de urbanização brasileiro proporcionou a exposição da população dos grandes centros (especialmente a população com poder aquisitivo) a riscos de desastres naturais, que conforme mencionado supra vem se concretizando nos últimos anos e provocando vultuosos danos materiais e humanos à população.

\section{Competências constitucionais do Estado em matérias ambiental e urbanística}

A Constituição da República de 1988 estabeleceu uma série de competências em matéria ambiental e urbanística a serem exercidas pelo Estado, por meio dos entes federados.

Ressalte-se o caput do artigo 225 o qual impõe ao Poder Público e à coletividade o dever de defender e preservar o meio ambiente ecologicamente equilibrado para as presentes e futuras gerações.

Nota-se que o poder público citado no caput do artigo 225 engloba todos os entes federados (União, Estados, Distrito Federal e Municípios), os três poderes (judiciário, legislativo e executivo), as autarquias, empresas públicas, entre outros.

O dever de proteger o meio ambiente possui intrínseca relação com os desastres naturais, ao passo que a destruição das infraestruturas verdes e as mudanças climáticas (alteração do meio ambiente natural) são fatores de 
vulnerabilização das comunidades aos impactos provenientes de fenômenos naturais.

No que tange ao meio ambiente a $\mathrm{CR} / 88$ determina, no que se refere à competência legislativa, que compete à União, aos Estados e ao Distrito Federal legislar concorrentemente sobre florestas, caça, pesca, fauna, conservação da natureza, defesa do solo e dos recursos naturais, proteção do meio ambiente e controle da poluição; proteção ao patrimônio histórico, cultural, artístico, turístico e paisagístico; responsabilidade por dano ao meio ambiente; e ao Município legislar sobre assuntos de interesse local.

Com relação à competência administrativa, a CR/88 atribui competência comum a União, aos Estados, ao Distrito Federal e aos Municípios para proteger bens de valor histórico, artístico e cultural, os monumentos, as paisagens naturais notáveis e os sítios arqueológicos; proteger o meio ambiente e combater a poluição em qualquer de suas formas; preservar as florestas, a fauna e a flora.

As florestas, mangues, matas ciliares, topos de morros, áreas permeáveis, vegetações de encostas de morros são infraestruturas naturais que prestam serviços ecossistêmicos à comunidade que mitigam os riscos de desastres naturais. A proteção do meio ambiente, combate a poluição e preservação da flora são competências de todos os entes federados, que se não observadas resultarão na destruição das infraestruturas naturais e em mudanças climáticas que favorecerão exponencialmente a ocorrência de desastres. Referidos entes federados, se comprovado que a destruição das infraestruturas naturais contribuiu para a ocorrência de um desastre natural, deverão ser responsabilizados civilmente, em respeito ao disposto nos artigos 225, §3으 e 37, §6으.

Relativamente à matéria urbanística indubitavelmente foi o Município o eleito pela $\mathrm{CR} / 88$ para deter as maiores competências. O artigo 30, inciso VIII determina que compete ao Município a promoção do adequado ordenamento territorial, mediante planejamento e controle do uso, do parcelamento e da ocupação do solo urbano. $O$ artigo 182 estabelece que a política de desenvolvimento urbano, executada pelo Poder Público municipal, conforme diretrizes gerais fixadas em lei têm por objetivo ordenar o pleno 
desenvolvimento das funções sociais da cidade e garantir o bem-estar de seus habitantes.

Quando os responsáveis pela ocorrência de desastres naturais forem justamente fatores urbanísticos como a desordenada ocupação do solo, indispensável será a responsabilização do ente municipal, visto que a esse cabe promover o adequado ordenamento do solo urbano de modo a proporcionar o pleno desenvolvimento das funções sociais da cidade e o bem estar de seus habitantes, o que não coaduna com a exposição a riscos de morte e de danos patrimoniais.

\section{Deveres do Estado na ordenação do território urbano e na prevenção de desastres naturais}

A Constituição da República de 1988 atribuiu algumas competências ao Estado no que concerne à ordenação do território urbano, principalmente à União e aos Municípios.

A legislação infraconstitucional encarregou-se de delimitar os deveres do Estado na ordenação do território urbano e na prevenção de desastres naturais, mais precisamente na Lei $n^{\mathrm{a}}$ 10.257/2001, vulgarmente conhecida como Estatuto da Cidade e na Lei no 12.608/2012 que instituiu a Política Nacional de Proteção e Defesa Civil - PNPDEC.

O Estatuto da Cidade estabelece como diretrizes da política urbana o planejamento do desenvolvimento das cidades, da distribuição espacial da população e das atividades econômicas do Município e do território sob sua área de influência, de modo a evitar e corrigir as distorções do crescimento urbano e seus efeitos negativos sobre o meio ambiente (efeitos negativos esses dentre os quais se destacam a criação de áreas potencialmente sujeitas a risco de desastres naturais e o aumento da vulnerabilidade das áreas de risco já existentes). Determina também a ordenação e controle do uso do solo, de forma a evitar a exposição da população a riscos de desastres; a proteção, preservação e recuperação do meio ambiente natural e construído, do patrimônio cultural, histórico, artístico, paisagístico e arqueológico, o que se concretizado manteria os serviços ecossistêmicos das infraestruturas naturais 
existentes e consequentemente minimizaria 0 potencial destruidor dos impactos oriundos dos fenômenos naturais.

A lei 10.257/2001 atribuiu a União a competência para, entre outros assuntos de interesse da política urbana, "legislar sobre normas gerais de direito urbanístico; legislar sobre normas para a cooperação entre a União, os Estados, o Distrito Federal e os Municípios em relação à política urbana, tendo em vista o equilíbrio do desenvolvimento e do bem-estar em âmbito nacional; promover, por iniciativa própria e em conjunto com os Estados, o Distrito Federal e os Municípios, programas de construção de moradias e a melhoria das condições habitacionais e de saneamento básico; instituir diretrizes para o desenvolvimento urbano, inclusive habitação, saneamento básico e transportes urbanos; elaborar e executar planos nacionais e regionais de ordenação do território e de desenvolvimento econômico e social". (BRASIL, 2001)

No que tange à atuação municipal na ordenação do território urbano, o Estatuto das Cidades reitera a Constituição da República ao determinar ao Município a elaboração do Plano Diretor, instrumento básico da política de desenvolvimento e expansão urbana.

A Lei 12.608/2012 alterou o Estatuto da Cidade e incluiu a obrigatoriedade do plano diretor para as cidades incluídas no cadastro nacional de Municípios com áreas suscetíveis à ocorrência de deslizamentos de grande impacto, inundações bruscas ou processos geológicos ou hidrológicos correlatos. O plano diretor das cidades incluídas no cadastro em tela devera conter "mapeamento contendo as áreas suscetíveis à ocorrência de deslizamentos de grande impacto, inundações bruscas ou processos geológicos ou hidrológicos correlatos; planejamento de ações de intervenção preventiva e realocação de população de áreas de risco de desastre; medidas de drenagem urbana necessárias à prevenção e à mitigação de impactos de desastres; identificação e diretrizes para a preservação e ocupação das áreas verdes municipais, quando for o caso, com vistas à redução da impermeabilização das cidades". (BRASIL, 2012)

Nota-se a preocupação com a manutenção das infraestruturas naturais, no caso com a permeabilidade do solo. 
No artigo 42-B o Estatuto da Cidade determina aos municípios que pretenderem expandir seu perímetro urbano, que delimitem os trechos com restrições à urbanização e os trechos sujeitos a controle especial em função de ameaça de desastres naturais, mais uma medida municipal a fim de prevenir futuros riscos.

A Lei 12.608/2012 vulgarmente conhecida como Lei da Política Nacional de Proteção e Defesa Civil inovou o ordenamento jurídico brasileiro aos inserir regras específicas sobre gestão de desastres. Determina referida lei que é dever da União, dos Estados, do Distrito Federal e dos Municípios adotar as medidas necessárias à redução dos riscos de desastre, sendo que a incerteza quanto ao risco de desastre não constituirá óbice para a adoção das medidas preventivas e mitigadoras da situação de risco. Percebe-se claramente a opção pelo princípio da precaução pela legislação em análise.

A PNPDEC abrange as ações de prevenção, mitigação, preparação, resposta e recuperação voltadas à proteção e defesa civil, havendo, no entanto, a opção pela prioridade às ações preventivas relacionadas à minimização de desastres.

Os objetivos da PNPDEC são elencados no artigo 5o, incisos I a XV, quais sejam:

I - reduzir os riscos de desastres;

II - prestar socorro e assistência às populações atingidas por desastres;

III - recuperar as áreas afetadas por desastres;

IV - incorporar a redução do risco de desastre e as ações de proteção e defesa civil entre os elementos da gestão territorial e do planejamento das políticas setoriais;

$\mathrm{V}$ - promover a continuidade das ações de proteção e defesa civil;

VI - estimular o desenvolvimento de cidades resilientes e os processos sustentáveis de urbanização;

VII - promover a identificação e avaliação das ameaças, suscetibilidades e vulnerabilidades a desastres, de modo a evitar ou reduzir sua ocorrência;

VIII - monitorar os eventos meteorológicos, hidrológicos, geológicos, biológicos, nucleares, químicos e outros potencialmente causadores de desastres;

IX - produzir alertas antecipados sobre a possibilidade de ocorrência de desastres naturais;

$X$ - estimular o ordenamento da ocupação do solo urbano e rural, tendo em vista sua conservação e a proteção da vegetação nativa, dos recursos hídricos e da vida humana;

XI - combater a ocupação de áreas ambientalmente vulneráveis e de risco e promover a realocação da população residente nessas áreas; 


\begin{abstract}
XII - estimular iniciativas que resultem na destinação de moradia em local seguro;

XIII - desenvolver consciência nacional acerca dos riscos de desastre; XIV - orientar as comunidades a adotar comportamentos adequados de prevenção e de resposta em situação de desastre e promover a autoproteção; e

$X V$ - integrar informações em sistema capaz de subsidiar os órgãos do SINPDEC na previsão e no controle dos efeitos negativos de eventos adversos sobre a população, os bens e serviços e o meio ambiente. (BRASIL, 2012)
\end{abstract}

Para alcançar os objetivos propostos a Lei 12.608/2012 distribuiu algumas competências aos entes federados.

Dentre os deveres estipulados pela PNPDEC para a União, destacam-se a promoção de estudos referentes às causas e possibilidades de ocorrência de desastres de qualquer origem, sua incidência, extensão e consequência; o apoio aos Estados, ao Distrito Federal e aos Municípios no mapeamento das áreas de risco, nos estudos de identificação de ameaças, suscetibilidades, vulnerabilidades e risco de desastre e nas demais ações de prevenção, mitigação, preparação, resposta e recuperação; a instituição e manutenção de sistema de informações e monitoramento de desastres; a instituição e manutenção cadastro nacional de municípios com áreas suscetíveis à ocorrência de deslizamentos de grande impacto, inundações bruscas ou processos geológicos ou hidrológicos correlatos; a instituição e manutenção sistema para declaração e reconhecimento de situação de emergência ou de estado de calamidade pública; a instituição do Plano Nacional de Proteção e Defesa Civil; a realização do monitoramento meteorológico, hidrológico e geológico das áreas de risco, bem como dos riscos biológicos, nucleares e químicos, e a produção de alertas sobre a possibilidade de ocorrência de desastres, em articulação com os Estados, o Distrito Federal e os Municípios. (BRASIL, 2012)

Aos Estados compete instituir o Plano Estadual de Proteção e Defesa Civil; identificar e mapear as áreas de risco e realizar estudos de identificação de ameaças, suscetibilidades e vulnerabilidades, em articulação com a União e os Municípios; realizar o monitoramento meteorológico, hidrológico e geológico das áreas de risco, em articulação com a União e os Municípios; apoiar a União, quando solicitado, no reconhecimento de situação de emergência e 
estado de calamidade pública; apoiar, sempre que necessário, os Municípios no levantamento das áreas de risco, na elaboração dos Planos de Contingência de Proteção e Defesa Civil e na divulgação de protocolos de prevenção e alerta e de ações emergenciais. (BRASIL, 2012)

Os Municípios foram incumbidos de identificar e mapear as áreas de risco de desastres; promover a fiscalização das áreas de risco de desastre e vedar novas ocupações nessas áreas; declarar situação de emergência e estado de calamidade pública; vistoriar edificações e áreas de risco e promover, quando for o caso, a intervenção preventiva e a evacuação da população das áreas de alto risco ou das edificações vulneráveis; organizar e administrar abrigos provisórios para assistência à população em situação de desastre, em condições adequadas de higiene e segurança; manter a população informada sobre áreas de risco e ocorrência de eventos extremos, bem como sobre protocolos de prevenção e alerta e sobre as ações emergenciais em circunstâncias de desastres; prover solução de moradia temporária às famílias atingidas por desastres. (BRASIL, 2012)

Percebe-se que as competências mais importantes com relação à prevenção de desastres são destinadas à União e principalmente ao Município, como o mapeamento e fiscalização das áreas de risco e a realocação das pessoas residentes em áreas de alto risco ou em edificações vulneráveis. Se os danos ocorridos nos desastres naturais resultarem da omissão estatal nas tarefas impostas pela PNPDEC e pelo Estatuto das Cidades, necessária será a averiguação de responsabilidade civil, razão pela qual, passar-se-á ao estudo do referido instituto.

\section{Aspectos gerais da responsabilidade civil}

A palavra responsabilidade tem sua origem no latim responsus, do verbo respondere que significa responder, pagar, designando uma ideia de reparar, recuperar, restituir ou ressarcir. (LEITE; AYALA, 2010)

Conceitualmente Silvio Rodrigues aduz que a responsabilidade civil é a "obrigação que pode incumbir uma pessoa a reparar o prejuízo causado a outra, por fato próprio, ou por fato de pessoas ou coisas que dela dependam", 
denotando uma clara intenção por parte do instituto do dever de se impor ao causador de um dano o dever de repará-lo ao prejudicado. (RODRIGUES, 2008, p.6)

A responsabilidade civil origina-se de duas fontes, quais sejam, 0 contrato ou a lei. A responsabilidade civil contratual é aquela que deriva do descumprimento de um acordo de vontade pactuado pelas partes, nessa modalidade há um vínculo jurídico entre o causador do dano e a vitima resultante de um negócio jurídico. Já a responsabilidade civil extracontratual ou aquiliana fundamenta-se na inobservância da lei, "na responsabilidade extracontratual, o agente infringe um dever legal" e como consequência provoca um dano a outrem. (GONÇALVES, 2007, p.21)

A responsabilidade civil subdivide-se em subjetiva e objetiva. A responsabilidade civil subjetiva, também denominada de "teoria da culpa" utiliza como fundamento da obrigação de reparar o dano a culpa lato sensu (dolo ou culpa, essa designada pela negligência, imprudência ou imperícia) do agente. Conforme aduz Clarisse Ferreira Jardim "a culpa é pressuposto decisivo, determinante, para a caracterização desta espécie de responsabilidade civil", que possui como elementos essenciais a conduta comissiva ou omissiva dotada de dolo ou culpa por parte do agente, o dano suportado pela vítima e o nexo de causalidade entre referida conduta e o citado dano. (JARDIM, 2010, p.63)

No que tange à responsabilidade objetiva, essa caracteriza-se pela dispensa da culpa para a sua incidência. A responsabilidade civil objetiva possui como elementos essenciais a conduta omissiva ou comissiva, o dano e o nexo de causalidade.

\subsection{Responsabilidade civil estatal}

A responsabilidade civil incide no ordenamento jurídico brasileiro sobre os particulares, pessoas físicas e jurídicas e sobre o Estado, este representado pelas pessoas jurídicas de direito público interno: entes federativos, autarquias, demais entidades de caráter público criadas por lei. 
Yussef Cahali sustenta que a responsabilidade civil do Estado é a obrigação legal que lhe é imposta "de ressarcir os danos causados a terceiros por suas atividades." (CAHALI, 2007, p.13)

A responsabilidade civil estatal rege-se pelo caráter objetivo conforme exposto no artigo 37, §6 da CR/88:

\begin{abstract}
Art. 37. A administração pública direta e indireta de qualquer dos Poderes da União, dos Estados, do Distrito Federal e dos Municípios obedecerá aos princípios de legalidade, impessoalidade, moralidade, publicidade e eficiência e, também, ao seguinte:

$\S 60$ - As pessoas jurídicas de direito público e as de direito privado prestadoras de serviços públicos responderão pelos danos que seus agentes, nessa qualidade, causarem a terceiros, assegurado o direito de regresso contra o responsável nos casos de dolo ou culpa. (BRASIL, 2009)
\end{abstract}

Reiterando a opção constitucional pela responsabilidade civil objetiva do Estado, o artigo 43 do Código Civil de 2002 determina que:

Art. 43. As pessoas jurídicas de direito público interno são civilmente responsáveis por atos dos seus agentes que nessa qualidade causem danos a terceiros, ressalvado direito regressivo contra os causadores do dano, se houver, por parte destes, culpa ou dolo. (BRASIL, 2002)

Ocorre que a responsabilização objetiva do Estado é recente, ao longo dos anos sucederam-se diversas alterações no que concerne à responsabilidade civil do Estado, como demonstrar-se-á a seguir.

\title{
5.1.1 Evolução da responsabilidade civil estatal
}

A responsabilidade civil do Estado sofreu diversas alterações ao longo dos séculos, passando da irresponsabilidade absoluta a responsabilidade subjetiva e finalmente a responsabilidade objetiva.

Nos Estados absolutistas na primeira metade do século XIX foi criada a teoria da irresponsabilidade absoluta do Estado, também conhecida como responsabilidade feudal, regalista ou regaliana. Essa teoria era baseada na ideia de soberania estatal e "confirmava a autoridade incontestável do ente perante os administrados, sendo inconcebível o Estado aparecer como 
transgressor, posto que este era o próprio direito organizado". (JARDIM, 2010, p.63) Nesse contexto os atos ilícitos praticados por funcionários públicos no exercício da função eram tidos como atos praticados em nome próprio, ensejando exclusivamente a responsabilidade pessoal dos mesmos.

Na segunda metade do século XIX surge a teoria civilista, na qual a responsabilidade civil do Estado tinha como pressuposto uma ação culposa dos funcionários públicos. Caso ausente o elemento culpa não havia que se falar em responsabilidade civil estatal.

A teoria civilista da responsabilidade civil estatal esteve presente no Código Civil de 1916 e nas Constituições de 1934 e 1937, até que em 1946 a Constituição adotou a responsabilidade civil objetiva para o Estado.

A teoria objetiva da responsabilidade civil do Estado baseia-se na desnecessidade da ocorrência de culpa do agente público para a imputação da obrigação de reparar o dano, bastando a presença de um comportamento, um dano e o nexo de causalidade entre ambos.

A responsabilidade objetiva do estado foi adotada pela Constituição da República de 1988 em seu artigo 37, §6 e pelo Código Civil em seu artigo 43, conforme já citado, porém os dispositivos em tela não demonstram claramente se tal modalidade de responsabilidade estende-se também aos danos resultados da omissão do Estado.

\subsubsection{Responsabilidade do Estado por omissão}

A responsabilidade civil estatal pode ocorrer em casos de ação ou omissão. No que concerne à responsabilidade derivada de conduta comissiva a doutrina é pacífica em aceitar a responsabilidade objetiva, variando apenas quanto à modalidade, risco administrativo ou risco integral. Já no que tange à responsabilidade civil em casos de omissão do Estado existe divergência doutrinária quanto ao caráter subjetivo ou objetivo da responsabilidade estatal.

Celso Antônio Bandeira de Mello afirma que "é razoável que o Estado responda objetivamente pelos danos que causou, mas só é razoável e impositivo que responda pelos danos que não causou quando estiver de direito obrigado a impedi-los". (BANDEIRA DE MELLO, 2010, p. 1014) 
Se o Estado não agiu, não pode ser autor do dano. E se não foi o autor, só cabe responsabilizá-lo caso esteja obrigado a impedir o dano, isto é, no caso de descumprimento de um dever legalmente imposto. Logo, a responsabilidade por ato omissivo do Estado seria sempre responsabilidade por um ato ilícito proveniente de negligencia, imprudência ou imperícia (culpa), o que remete à responsabilização com base na teoria da responsabilidade subjetiva. Nesse caso, a responsabilidade Estatal não restaria configurada apenas pela demonstração da ausência do serviço e o dano sofrido, dependendo da imposição legal de atuação Estatal naquela circunstância, sob pena de excessiva e abusiva punição. (BANDEIRA DE MELLO, 2010, p. 1014)

De fato não é razoável exigir do Estado que indenize alguém por dano resultante da abstenção de uma atividade que não Ihe incumbia realizar, consequentemente, se o Estado for responsabilizado por deixar de fazer algo que por exigência legal deveria fazer haverá indiscutivelmente culpa, seja por negligência, imprudência ou imperícia.

Respeitável parte da doutrina, no entanto, defende a responsabilidade objetiva nos casos de omissão estatal, como Hely Lopes Meirelles e José de Aguiar Dias.

Os elementos da responsabilidade civil por omissão estatal são a omissão do Estado em realizar dever legalmente the atribuído e o dano provocado a outrem decorrente desta omissão. Verificados ambos os elementos terá caracterizada a responsabilidade civil do Estado por omissão.

Há que se ressaltar as duas modalidades de omissão citadas pela doutrina, quais sejam, omissão genérica e omissão específica.

A omissão genérica decorre do mero dever legal do Poder Público de fazer algo, independentemente da existência de uma possibilidade efetiva de concretização deste dever. É o que ocorre com o dever do Estado de proteger o meio ambiente.

Quanto à omissão específica, entende-se essa como aquela que se concretiza quando o Estado diante de uma possibilidade fática de atuação, em que deve agir de modo a evitar ou prevenir o dano, deixa de fazê-lo, como acontece quando em uma fiscalização que se constate a existência de pessoas residindo em áreas de risco muito alto de deslizamentos, deixa de realocá-los conforme determina a lei 12.608/2012. 


\title{
5.2 Responsabilidade civil em matéria ambiental e a omissão estatal nos casos de desastres naturais
}

A Lei oㅡ 6.938/1981 que instituiu a Política Nacional do Meio Ambiente reservou artigo próprio para a responsabilidade civil em matéria ambiental, estabelecendo que os responsáveis por danos ao meio ambiente, sejam eles particulares ou o poder público, terão que indenizá-los independentemente de culpa.

O artigo 14, § $1^{\text {o }}$ do referido diploma determina:

\begin{abstract}
Art. 14 - Sem prejuízo das penalidades definidas pela legislação federal, estadual e municipal, o não cumprimento das medidas necessárias à preservação ou correção dos inconvenientes e danos causados pela degradação da qualidade ambiental sujeitará os transgressores:

$\S 1^{\circ}$ - Sem obstar a aplicação das penalidades previstas neste artigo, é o poluidor obrigado, independentemente da existência de culpa, a indenizar ou reparar os danos causados ao meio ambiente e a terceiros, afetados por sua atividade. O Ministério Público da União e dos Estados terá legitimidade para propor ação de responsabilidade civil e criminal, por danos causados ao meio ambiente. (BRASIL, 1981)
\end{abstract}

Percebe-se que na seara ambiental vigora a responsabilidade civil objetiva, sendo que os danos causados ao meio ambiente deverão ser reparados independentemente de culpa do degradador.

Quando o Estado for o causador do dano ambiental a responsabilidade objetiva possui dupla fundamentação, tanto no que concerne à responsabilidade civil estatal, de caráter objetivo como já visto, quanto pela responsabilidade civil objetiva em matéria ambiental.

É notório que os danos provocados por desastres naturais possuem considerável contribuição do Estado, por meio da sua omissão no dever de ordenar adequadamente o solo urbano; fiscalizar as áreas de risco a fim de evitar a continuidade da sua ocupação; realocar a população residente em área de alto risco; impedir a retirada das matas ciliares, de encostas e topos de morros; promover adequado sistema de drenagem de aguas pluviais; evitar a 
impermeabilização excessiva do solo; entre outros deveres de prevenção a desastres naturais já citados em capítulo próprio.

Todos esses deveres estatais estão previstos nas Leis 10.257/2001 (Estatuto da Cidade) e 12.608/2012 (Política Nacional de Proteção e Defesa Civil), a omissão desses deveres potencializa os impactos provenientes dos fenômenos naturais, ocasionando diversos danos patrimoniais (destruição de moradias e móveis domésticos, por exemplo) e extrapatrimoniais (óbitos, enfermidades, ferimentos, entre outros), além dos danos ambientais como destruição de matas ciliares, de vegetações de encostas e do assoreamento de rios, que potencializarão futuros desastres naturais, formando um círculo vicioso de potencialização de riscos.

É importante mencionar que não apenas o dano patrimonial e extrapatrimonial ambiental deverão ser indenizados pelo poder público, mas também os danos ao patrimônio privado e a esfera pessoal dos afetados, resultantes dos fenômenos naturais e da inércia do poder público. Referidos danos à esfera pessoal dos afetados decorrentes do dano ambiental são denominados dano por ricochete e possuem o mesmo tratamento dispensado ao dano ambiental no que concerne à responsabilização objetiva por sua reparação.

\subsection{Teoria do Risco Administrativo x Teoria do Risco Integral}

A teoria objetiva da responsabilidade civil estatal subdivide-se em teoria do risco administrativo e teoria do risco integral.

A possibilidade de afastamento da responsabilidade civil do Estado mediante as excludentes do nexo causal consubstancia-se na maior diferença entre a teoria do risco administrativo e a teoria do risco integral.

Para a teoria do risco integral a simples verificação do prejuízo sofrido pelo administrado em consequência da conduta do poder público implica o dever de reparação, não havendo qualquer possibilidade de exclusão do nexo de causalidade. Conforme Carvalho "a teoria do risco integral [...] obriga a reparação de todo e qualquer dano, não admitindo nenhuma causa de excludente de responsabilidade". (CARVALHO, DAMACENA, 2013, p.125) 
Cavalieri Filho aduz que "a teoria do risco administrativo importa em atribuir ao Estado a responsabilidade pelo risco criado pela sua atividade administrativa". Segundo o autor "toda lesão sofrida pelo particular deve ser ressarcida, independentemente de culpa do agente público que a causou. $O$ que se tem que verificar é, apenas, a relação de causalidade entre a ação administrativa e o dano sofrido pelo administrado". (CAVALIERI FILHO, 2010, p.243)

Para Morato Leite e Patryck Ayala:

\begin{abstract}
Entende-se por riscos criados, os produzidos por atividades e bens dos agentes que multiplicam, aumentam ou potencializam um dano ambiental. O risco criado tem lugar quando uma pessoa faz uso de mecanismos, instrumentos ou de meios que aumentam o perigo de dano. Nestas hipóteses, as pessoas que causaram dano respondem pela lesão praticada, devido à criação de risco ou perigo, e não pela culpa. (LEITE; AYALA, 2010, p.132)
\end{abstract}

Carvalho e Damacena asseveram que a teoria do risco administrativo permite ao Estado afastar sua responsabilidade nos casos de exclusão do nexo causal entre sua conduta e o dano, mediante as excludentes de fato exclusivo da vítima, caso fortuito e força maior e fato exclusivo de terceiro. (CARVALHO, DAMACENA, 2013)

Em razão de não conceber-se a caracterização do Estado como um garantidor universal admite-se ao mesmo eximir-se da responsabilidade de reparar o dano em casos de excludentes de ilicitude como a culpa exclusiva da vítima. Com relação ao fato exclusivo de terceiro e ao caso fortuito e força maior importante tecer alguns comentários.

Primeiramente cabe distinguir caso fortuito e força maior. Embora não haja consenso na doutrina com relação à conceituação de ambos, entende-se por força maior o evento externo ao serviço público, decorrente de fato natural, tendo como pressupostos a irresistibilidade e a exterioridade e eventualmente a imprevisibilidade. Com relação ao caso fortuito esse ocorre quando do acontecimento de evento imprevisível interno ao funcionamento da atividade estatal que seja imprevisível e inevitável.

Nos casos de desastres naturais é recorrente a arguição de força maior por parte do Estado para imiscuir-se da responsabilidade de reparar os danos. 
Ocorre que com o avanço da tecnologia os fenômenos naturais são cada vez mais previsíveis e como anualmente a intensidade desses fenômenos vem se acentuando, é provável que eventos mais intensos do que os já ocorridos venham a acontecer, e consequentemente provoquem danos mais intensos dos que os até então já verificados. Nesses casos acredita-se que apenas aqueles eventos que a ciência não possua meios de prevenção (inevitáveis, irresistíveis) sejam capazes de provocar a exclusão do nexo de causalidade por omissão estatal, como, por exemplo, a queda de um meteoro ou um incêndio florestal provocado pela queda de um raio, visto que mesmo com a ciência da queda de um meteoro ou da ocorrência de uma tempestade de raios, não existem mecanismos capazes de impedir os impactos provocados por tais fenômenos.

No que tange à ocorrência de casos fortuitos (morte em massa de agentes de defesa civil ou incêndio em galpão de suprimentos) que impeçam o cumprimento das obrigações legais em casos de desastres por parte do Estado, acredita-se que o mesmo não poderá eximir-se da responsabilidade de reparação dos danos em virtude do princípio da eficiência da atuação estatal, previsto no caput do artigo 37 da $\mathrm{CR} / 88$, do qual se depreende que o Estado deve possuir um aparato capaz de arcar com eventuais adversidades decorrentes de sua estrutura interna.

No caso da excludente fato exclusivo de terceiro, defende-se que como o Estado tem o dever constitucional de proteger e preservar o meio ambiente, não pode permitir que determinada pessoa o deteriore a ponto de provocar danos a outrem. Caso isso ocorra ao Estado caberá indenizar a vítima, em razão de sua omissão na fiscalização do comportamento degradador alheio e de seu grande poder econômico, restando o direito de regresso contra 0 terceiro causador do dano.

Percebe-se então que em casos de desastres naturais, apenas a culpa exclusiva da vítima e eventualmente a força maior serão aptos a excluir o nexo de causalidade entre a omissão estatal e o dano causado, visto que o avanço da tecnologia e a probabilidade de fenômenos naturais cada vez mais intensos eliminam a possibilidade de exclusão por força maior em grande parte dos casos e o dever genérico de proteger o meio ambiente e promover o direito de 
todos ao meio ambiente ecologicamente equilibrado extirpa a possibilidade de afastamento da responsabilidade nos casos de fato exclusivo de terceiro.

Importante mencionar que o nexo de causalidade entre a conduta omissiva ou comissiva do Estado e o dano decorrente dos impactos provocados por eventos adversos é indispensável, ou seja, deve ser demonstrado que referido comportamento comissivo ou omissivo do Estado potencializou o poder destruidor dos fenômenos naturais. Ocorre que como $o$ poder público possui notoriamente mais meios de produção de provas, a mera verossimilhança do alegado pelos afetados deve ser apta a provocar a inversão do ônus da prova em face do Estado, de modo a proporcionar uma relação mais equânime entre a Administração e o administrado.

\section{A complexidade do nexo causal em matéria ambiental e a Teoria da Probabilidade}

Não obstante o Estado responda pelos danos causados por sua inércia, mesmo que esses tenham ocorrido não exclusivamente em decorrência dela, demonstrar o nexo de causalidade entre a ausência de conduta estatal e o dano não é tarefa fácil.

A prova do nexo de causalidade entre a omissão estatal e o dano ecológico (esse incluindo o dano ambiental ou ecológico puro e o dano à esfera pessoal do afetado ou dano por ricochete) não é simples, em razão da cumulatividade e da extensão temporal dos fatores desencadeadores do dano.

A fim de evitar a irresponsabilidade por danos ambientais nos casos em que não há certeza científica de quem e em que proporção provocou o dano, surgiu na Espanha a Teoria das Probabilidades, que trata-se de um "instrumento hermenêutico destinado a facilitar a prova do nexo causal à vítima". (CARVALHO, 2013, p. 160)

Delton Winter de Carvalho assevera que a teoria das probabilidades é sensível à complexidade e às incertezas científicas que permeiam os danos ambientais, ao passo que determina que o legitimado ativo não terá que demonstrar o nexo de causalidade com exatidão científica, mas que a sua configuração se dará sempre que o juiz se convencer da existência de uma 
probabilidade determinante ou considerável da relação de causalidade entre a atividade e o dano. (CARVALHO, 2013)

Em consonância com a teoria das probabilidades sustenta Canotilho:

Só existe responsabilidade civil se houver provada a existência de uma relação causa-efeito entre $\circ$ fato e o dano. Esta relação de causalidade não tem que ser determinística, como uma relação mecânica, mas deve ser uma causalidade probabilística. Considerase que um determinado fato foi a causa de um determinado dano se, de acordo com as regras da experiência normal, aquele tipo de fato for adequado a causar aquele tipo de dano. (CANOTILHO, 1998, p. 142)

A teoria das probabilidades apresenta-se extremamente útil para a análise do nexo de causalidade dos danos ambientais decorrentes de desastres naturais, nos quais busca-se a responsabilização do Estado pela omissão dos seus deveres constitucionais de proteção do meio ambiente e adequada ordenação do território urbano, e dos deveres legais estabelecidos no Estatuto da Cidade e na PNPDEC.

Nesse aspecto mostrar-se-ia útil uma inversão no ônus da prova em face do Estado, cabendo a esse demonstrar a ausência do nexo de causalidade entre sua omissão e a concretização do dano, visto que o mesmo possui poderes infinitamente maiores do que os particulares afetados, o que the possibilita o maior acesso a meios de provar a ausência do nexo de causalidade, proporcionando então um equilíbrio entre as partes. Essa inversão do ônus da prova deve ocorrer apenas nos casos em que ficar demonstrada a verossimilhança do alegado pelos afetados no que tange à omissão estatal enquanto causa (ainda que concorrente) do dano sofrido.

Há que se mencionar que em casos de desastres naturais em que os danos ocorridos atinjam a esfera do mínimo existencial do ser humano, não há sequer que se perquirir o nexo de causalidade entre a omissão estatal e o dano causado, vide que o Estado brasileiro fundamenta-se pela dignidade humana e tem como objetivos a erradicação da pobreza e da marginalização e a redução das desigualdades sociais e regionais.

Nesse sentido Tiago Fernstenseifer: 


\begin{abstract}
O Estado brasileiro, independentemente da sua responsabilização pelos danos causados às vitimas de desastres naturais relacionados às mudanças climáticas, diante do seu papel constitucional de guardião dos direitos fundamentais e da dignidade da pessoa humana, tem o dever de assegurar a todas as pessoas condições mínimas de bem-estar (individual, social e ecológico). [...] O respeito e a proteção à dignidade humana necessitam do engajamento material do Estado, na medida em que a garantia da dignidade humana pressupõe uma pretensão jurídica prestacional do indivíduo ao mínimo existencial. [...] Sem o acesso a tais condições mínimas, não há que se falar em liberdade real ou fática, quanto menos em um padrão de vida compatível com a dignidade humana. A garantia do mínimo existencial (social e ecológico) constitui-se, em verdade de uma premissa ao próprio exercício dos demais direitos fundamentais, sejam eles direitos de liberdade, direitos sociais ou mesmo direitos de solidariedade, como é o caso do direito ao ambiente. (FERNSTENSEIFER, 2010, p.18-20)
\end{abstract}

Como a maioria dos desastres naturais ocorridos no país incidem em áreas ocupadas por populações de baixa renda, como favelas e aglomerações ribeirinhas, em que os afetados perdem suas casas e objetos pessoais, ficando muitas vezes completamente desamparados, em grande parte dos casos a busca pelo nexo de causalidade entre a omissão estatal e o dano será desnecessária ante a obrigação estatal de promoção do mínimo existencial, que nesses casos, resultará na obrigação de reparação dos danos sofridos.

\title{
7. Conclusão
}

A Teoria do Risco Administrativo é consagrada teoria no concernente à Responsabilidade Civil do Estado em matéria ambiental, por não conceber-se o Estado como um garantidor universal, razão pela qual não se admite juridicamente que o mesmo seja obrigado a reparar danos que não advieram de sua atividade ou de eventual inadimplemento de suas obrigações.

Nos casos de danos ambientais decorrentes da omissão do Estado, pugna-se pela responsabilização deste com base no critério subjetivo, visto que só é razoável responsabilizar o Estado pela omissão de uma atividade que ele está obrigado a fazer, o que já implica culpa, seja na modalidade negligência, imperícia ou imprudência.

Em consequência da adoção do critério subjetivo para a responsabilidade civil do Estado por omissão é indispensável a demonstração 
do nexo de causalidade entre o dano e a omissão estatal, o que nem sempre será fácil, em razão do caráter cumulativo e multifacetado do dano ambiental. Propõe-se, contudo, pela inexorável inversão do ônus da prova em desfavor do Estado nas ações indenizatórias promovidas por vítimas de desastres naturais, quando houver verossimilhança no alegado por essa (relativa ao nexo de causalidade entre a conduta do Estado e o dano sofrido) visto que esse possui maior acesso a mecanismos de prova, o que equilibra a relação processual entre referidas partes, homenageando-se a distribuição dinâmica do onus probandie a isonomia entre as partes.

Nos casos de danos decorrentes de desastres naturais, em decorrência do avanço tecnológico capaz de prever diversos fenômenos naturais, defendese que a exclusão do nexo de causalidade somente poderá ser ensejada em casos extremos de força maior, quando a ciência ainda não tiver meio de evitar o dano e nos casos de culpa exclusiva da vítima.

O caso fortuito (evento imprevisível interno ao funcionamento da atividade estatal que seja imprevisível e inevitável) e o fato exclusivo de terceiro não devem ser aptos a afastar a responsabilidade do Estado visto que esse deve atuar com eficiência e possuir um aparato capaz de arcar com eventuais adversidades decorrentes de sua estrutura interna e por possuir 0 dever constitucional de proteger e preservar o meio ambiente, o que não permite que abstenha-se de fiscalizar o comportamento das pessoas ao ponto delas serem capazes de deteriorar o meio ambiente. Caso isso ocorra, ao Estado caberá indenizar a vítima, em razão de sua omissão na fiscalização do comportamento degradador alheio e de seu grande poder econômico, restando o direito de regresso contra o terceiro causador do dano.

\section{Referências}

ANTUNES, Paulo de Bessa. Direito Ambiental. 12.ed. rev. ampl. refor. Rio de Janeiro: Lúmen Júris, 2010.

BANDEIRA DE MELLO, Celso Antônio. Curso de Direito Administrativo. São Paulo: Malheiros, 2010. 
Disponível em:

<http://bdjur.stj.gov.br/dspace/bitstream/2011/8632/3/A_Responsabilidade_Civil .pdf>. Acesso em: 19 set 2014.

BRASIL. Lei no 6.938, de 31 de Agosto de 1981. Dispõe sobre a Política Nacional do Meio Ambiente, seus fins e mecanismos de formulação e aplicação, e dá outras providências. Diário Oficial, Brasília, 02 set. 1981.

BRASIL. Lei no 10.257, de 10 de Julho de 2001. Regulamenta os arts. 182 e 183 da Constituição Federal, estabelece diretrizes gerais da política urbana e dá outras providências. Diário Oficial, Brasília, 11 jul. 2001.

BRASIL. Lei no 10.406, de 10 de Janeiro de 2002. Institui o Código Civil. Diário Oficial, Brasília, 11 jan. 2002.

BRASIL, Constituição da República Federativa do Brasil de 1988. 1. ed. Belo Horizonte: Editora Dictum, 2009.

BRASIL. Decreto 7.257, de 4 de Agosto de 2010. Regulamenta a Medida Provisória no 494 de 2 de julho de 2010, para dispor sobre o Sistema Nacional de Defesa Civil - SINDEC, sobre o reconhecimento de situação de emergência e estado de calamidade pública, sobre as transferências de recursos para ações de socorro, assistência às vítimas, restabelecimento de serviços essenciais e reconstrução nas áreas atingidas por desastre, e dá outras providências. Diário Oficial, 06 ago 2010

BRASIL. Lei 12.608, de 10 de Abril de 2012. Institui a Política Nacional de Proteção e Defesa Civil - PNPDEC; dispõe sobre o Sistema Nacional de Proteção e Defesa Civil - SINPDEC e o Conselho Nacional de Proteção e Defesa Civil - CONPDEC; autoriza a criação de sistema de informações e monitoramento de desastres; altera as Leis $n^{\text {os }} 12.340$, de $1^{\circ}$ - de dezembro de 2010, 10.257, de 10 de julho de 2001, 6.766, de 19 de dezembro de 1979, 8.239, de 4 de outubro de 1991, e 9.394, de 20 de dezembro de 1996; e dá outras providências. Diário Oficial, Brasília, 11 abr. 2012.

BRASIL. Ministério da Integração Nacional. Secretaria Nacional de Defesa Civil. Centro Nacional de Gerenciamento de Riscos e Desastres. Anuário brasileiro de desastres naturais: 2011 / Centro Nacional de Gerenciamento de Riscos e Desastres. - Brasília: CENAD, 2012.

BRASIL. Ministério da Integração Nacional. Secretaria Nacional de Defesa Civil. Centro Nacional de Gerenciamento de Riscos e Desastres. Anuário brasileiro de desastres naturais: 2012 / Centro Nacional de Gerenciamento de Riscos e Desastres. - Brasília: CENAD, 2013.

BRASIL. Ministério da Ciência e Tecnologia. Instituto Nacional de Pesquisas Espaciais - INPE. Desastres Naturais e Geotecnologias: Conceitos

Básicos. Versão preliminar. Santa Maria, 2007. 
BRASÍLIA. Ministério da Ciência e Tecnologia. Secretaria Nacional de Defesa Civil. Política Nacional de Defesa Civil. 2007.

CAHALI, Yussef Said. Responsabilidade civil do Estado. 3. ed. São Paulo: Revista dos Tribunais, 2007

CANOTILHO, José Joaquim Gomes. (coord.). Introdução ao Direito do Ambiente. Lisboa: Universidade Aberta, 1998.

CARVALHO, Delton Winter de. Dano Ambiental Futuro: A responsabilização civil pelo risco ambiental. $2^{\mathrm{a}}$ ed. revista, atualizada e ampliada. Porto Alegre: Livraria do Advogado, 2013

CARVALHO, Delton Winter de; DAMASCENA, Fernanda Libera. Direito dos Desastres. Porto Alegre: Livraria do Advogado, 2013.

CAVALIERI FILHO, Sergio. Programa de Responsabilidade Civil. 9ª ed. revista e ampliada. São Paulo: Atlas, 2010.

CONDE, Luiz Paulo. Cadernos de Ciência, São Paulo: FINEP, n. 28, p.13-15, jul./ago./set. 1992.

FERNANDES, Edésio. A nova ordem jurídico-urbanística no Brasil. In: FERNANDES, Edésio; ALFONSIN, Betânia (Org). Direito Urbanístico: estudos brasileiros e internacionais. Belo Horizonte: Del Rey, 2006.

FERNSTENSEIFER, Tiago. A responsabilidade do Estado pelos danos causados às pessoas atingidas pelos desastres ambientais associados as mudanças climáticas: uma análise à luz dos deveres de proteção ambiental do Estado e da proibição de insuficiência na tutela do direito fundamental ao ambiente. E-book Responsabilidade Civil e Mudança Climática. Planeta Verde, 2010.

GONÇALVES, Carlos Roberto. Responsabilidade Civil, 10. ed. São Paulo: Saraiva, 2007, p.21

JARDIM, Clarisse Ferreira. Responsabilidade Civil do Estado diante das catástrofes naturais. In: Direito \& Justiça. v. 36, n.1, p.61-82, jan/jun. 2010

LEITE, José Rubens Morato; AYALA, Patryck de Araújo. Dano Ambiental: Do individual ao coletivo extrapatrimonial. Teoria e prática. $3^{\mathrm{a}} \mathrm{ed}$. rev. atual. e ampl. São Paulo: Revista dos Tribunais, 2010.

NAÇÕES UNIDAS. Declaração do Rio sobre o Meio Ambiente e Desenvolvimento. Rio de Janeiro, 1992. Disponível em:

<http://www.onu.org.br/rio20/img/2012/01/rio92.pdf>. Acesso em 20 set. 2014.

RIO DE JANEIRO, Universidade Federal Rural do (UFRRJ). Mapa mental dos problemas das enchentes urbanas. Disponível em 
<http://www.ufrrj.br/institutos/it/de/acidentes/mma10.htm>. Acesso em 28 jul 2014.

RIOS, Mariza. Direito Constitucional à Moradia. In: RIOS, Mariza;

CARVALHO, Newton Teixeira de (coord). Direito à Cidade: Moradia e Equilíbrio Ambiental. Belo Horizonte: Del Rey, 2012.

ROLNIK, Raquel. A cidade e a lei: legislação, política urbana e territórios na cidade de São Paulo. São Paulo: Studio Nobel: FAPESP, 1997.

RODRIGUES, Silvio. Direito Civil. 20 ed. v. 4. São Paulo: Saraiva, 2008, p.6

SANTOS, Milton. A Urbanização Brasileira. 5. ed. São Paulo: Editora da Universidade de São Paulo, 2005.

SAMPAIO, José A. L.; WOLD, Chris.; NARDY, Afrânio. Princípios de Direito Ambiental na dimensão internacional e comparada. Belo Horizonte: Del Rey, 2003. 